\title{
Ueber das Hefetrypsin III.
}

Von

Fr. Kutscher.

(Aus dem physiologischen Institut in Marburg.)

(Der Redaction zugegangen am 5. Januar 1902.)

In Bd. XXXIII S. $385 \mathrm{ff}$. dieser Zeitschrift haben Hahn und Geret eine Erwiderung gegen mich veröffentlicht, die mancherlei Unrichtiges und Irriges enthält, wodurch ich gezwungen bin, auf dieselbe einzugehen. Ich muss mich zunächst gegen den Schlusssatz, mit dem sie die Abhandlung beenden, wenden. Sie schreiben darin: «Kutscher's Arbeiten haben wirklich etwas Neues gebracht. Gerade aber deshalb hätte er es auch gar nicht nöthig gehabt, die Fortschritte, die in den früher erschienenen Arbeiten anderer Autoren enthalten sind, zu negiren." Die kleinliche Absicht, die mir hier von Hahn und Geret untergeschoben wird, hat mir, wie ich sofort zeigen werde, völlig gefehlt. Entstanden ist der ganze Streit, den ich seit einiger Zeit gegen Salkowski, Hahn und Geret führe, durch nachstehende Sätze, die ich in den Sitzungsberichten der Gesellschaft zur Beförderung der gesammten Naturwissenschaften veröffentlicht habe. «Die ersten Angaben, welche auf das Vorhandensein starker proteolytischer Enzyme im Inneren der Hefezellen hinweisen, verdanken wir Schützenberger und Kossel. Die beiden genannten Forscher überliessen gewaschene Hefe der Selbstgährung bei $37-40^{\circ}$ und konnten danach eine starke Zunahme der wasserlöslichen Substanzen feststellen. Unter denselben fanden sie in reichlicher Menge Tyrosin, Leucin, freie Alloxurbasen und freie 
Phosphorsäure. Es sind das lauter Substanzen, die nur aus zersetzten Nucleinen und Eiweisskörpern der Hefe stammen konnten. Die folgenden Arbeiten von Salkowski und Hahn haben über die Natur des proteolytischen Enzyms in der Hefe und den Abbau, den die Eiweisskörper durch dasselbe erfahren, nichts wesentlich Neues ergeben.» Ich bin in diesen Sätzen eingetreten für die Verdienste Schützenberger's und Kossel's, deren Arbeiten von Salkowski, Hahn und Geret zum Theil überhaupt nicht gekannt oder nicht genügend hervorgehoben waren. Für meine eigene Arbeit war es vollkommen gleichgültig, ob ich unsere bisherigen Kenntnisse über das proteolytische Enzym der Hefe aus den Arbeiten Schützenberger's und Kossel's oder denen Salkowski's und Hahn's ableitete. Es wäre im. Gegentheil das Letztere vortheilhatter für mich gewesen, denn es wäre mir der ganze Streit, den ich voraussehen konnte, erspart geblieben. Wenn ich dennoch den von Salkowski und Hahn beanstandeten Passus nicht anders fasste, so habe ich es gethan, um den Arbeiten Schützenberger's und Kossel's die ihnen meiner Ansicht nach gebührende Geltung zu verschaffen. Ich musste dazu allerdings die Verdienste, die sich Salkowski, weiter Hahn und Geret um Entdeckung und Charakterisirung des proteolytischen Enzyms der Hefe zuschreiben, auf ihren wahren Werth zurückschrauben, aber irgend ein Gewinn konnte dabei für mich sich nicht ergeben, sondern derselbe lag. lediglich auf Seiten Schützenberger's. Deshalb waren eigensüchtige oder kleinliche Absichten bei meiner Arbeit von vornherein ausgeschlossen.

Nun wäre es ja für Hahn und Geret ein Leichtes gewesen, meine Behauptung, sie hätten bezüglich des proteolytischen Enzyms der Hefe nichts Neues gegeben, zu widerlegen. Sie hätten ja nur die neuen von ihnen gefundenen Thatsachen aufzuzählen brauchen. Statt dessen erheben sie drei Vorwürfe gegen mich, die zum Theil mit der eigentlichen Streitfrage gar nichts zu thun haben.

Sie werfen mir zunächst vor, dass ich mir die Kenntniss ihrer ausführlichen Arbeit über das proteolytische Enzym der 
Hefe nicht verschafft habe. Sie befinden sich dabei im Irrthum. Ihre Arbeit ist mir sehr gut bekannt gewesen. Ich konnte dieselbe aber in der Publication meines Vortrages «Die Selbstverdauung der Hefe" nicht berücksichtigen und citiren, denn mein Vortrag wurde am 20. Juni 1900 gehalten. Gedruckt war er am 25. Juni. Die Arbeit von Hahn und Geret erschien aber erst in dem Anfang August ausgegebenen Heft der Zeitschrift für Biologie. Es werden jetzt wohl auch Hahn und Geret verstehen, warum ich ihrer Arbeit in meinem Vortrag nicht gedenken konnte. Nun hätte ich sie allerdings bei meiner ausführlichen Veröffentlichung über die Selbstgährung der Hefe erwähnen können. Wir citiren jedoch bekanntlich nur Arbeiten, denen wir irgend einen Einfluss auf unsere cigene Arbeit zugestehen. Mir aber war es beim besten Willen unmöglich, der Arbeit von Hahn und Geret auch nur einen Gedanken oder eine richtige Methode zu entnehmen. Oder sollte ich etwa, wie sie, das bei der Selbstverdauung der Hefe sich bildende Leucin zur Darstellung empfehlen, während wir doch aus den Arbeiten von Schützenberger wissen, dass es nie rein, sondern stets durch eine schwefelhaltige Substanz (wahrscheinlich Cystin resp. Cystein) verunreinigt zu gewinnen ist?

Oder sollte ich ihre Methode zur Bestimmung der verschiedenen Spaltungsprodukte, die sich ungefähr mit der falschen von Hausmann unter Hofmeister's Leitung ausgearbeiteten deckt, benutzen?

Oder sollte ich mir gar ihre Ansichten über den Abbau des Eiweisses durch Trypsin zu eigen machen, in denen noch immer das bereits legendär gewordene Antipepton eine grosse Rolle spielte?

Des Weiteren werfen sie mir vor, den Zweck ihrer Untersuchungen nicht richtig gewürdigt zu haben. Um diesen Vorwurf zu erläutern, versuchen sie mich darüber $\mathrm{zu}$ belehren, dass das Studium der Enzymwirkung an dem nach Buchner's Methode dargestellten zellfreien Presssaft gewinnbringender und erfolgreicher ist, wie das Studium an Material, das abgetödtete Zellen enthält. Diese Ausführungen berühren unseren Streit 
eigentlich gar nicht. Im Uebrigen sind sie nur sehr bedingt richtig, denn dass man auch mit zellhaltigem Material recht beachtenswerthe Resultate erzielen kann, haben die erst kürzlich veröffentlichten Arbeiten $L$ awrow's ${ }^{1}$ ) über die Wirkungsweise des Pepsins ergeben. Im ferneren Verlauf ihrer Arbeit sprechen mir dann Hahn und Geret das Recht ab; das proteolytische Hefeenzym als Hefetrypsin zu bezeichnen. Ein Bestreben, das mir höchst merkwürdig erscheint. Denn nachdem ich als Erster den Beweis dafür erbracht hatte, dass die Wirkungsweise des proteolytischen Hefeenzyms durchaus identisch ist mit der des Pankreastrypsins, da sollte mir das Recht, es als Hefetrypsin zu bezeichnen, nicht zustehen? Umgekehrt könnte ich viel eher meine Verwunderung darüber ausdrücken, wie Hahn und Geret dazu kommen, das proteolytische Enzym der Hefe Hefeendotrypsin zu nennen, während doch ihre Versuche scheinbar auf tiefgreifende Unterschiede zwischen Pankreastrypsin und dem proteolytischen Enzym der Hefe hinweisen.

Die Behauptung endlich, Wroblewski habe bereits unter den Spaltungsprodukten, die bei der Selbstverdauung der Hefe entstehen, Asparaginsäure und Glutaminsäure nachgewiesen, ist zum Theil direkt falsch. Wroblewski erwähnt die Asparaginsäure überhaupt nicht, sondern nur die Glutaminsäure. Mir ist im Gegensatz zu den Angaben von Wroblewski es wohl gelungen, reichlich Asparaginsäure unter den Verdauungsprodukten nachzuweisen, dagegen habe ich niemals auch nur eine Spur Glutaminsäure erhalten können, trotzdem ich $\mathrm{Me}$ thoden benutzte, die von mir ausgearbeitet und den bisher zur Isolirung der Glutaminsäure bekannt gegebenen weit überlegen waren. Es würde mich daher ausserordentlich interessiren, wenn mir $\mathrm{Hahn}$ und $\mathrm{Geret}$ die Methode angeben wollten, - nach der Wroblewski die Glutaminsäure gewonnen hat.

Schliesslich sagen Hahn und Geret, ich hätte ihnen in der Frage des proteolytischen Enzyms der Tuberkelbacillen eine falsche Unterstellung gemacht. In meiner Arbeit, in der

1) Diese Zeitschrift, Bd. XXXIII, S. 312. 
ich dies gethan haben soll, bemängeln sie zunächst die ungenauen Angaben über das Alter der von mir benutzten Tuberkelbacillen. Sie kritisiren es abfällig, dass ich die verwandten Tuberkelbacillenculturen nur als "frisch * bezeichnet habe. Nachdem die Herren nunmehr hieran Anstand genommen haben, glaube ich ihnen Folgendes verrathen zu dürfen. Ich habe mir ihre eigenen Arbeiten in diesem einen Punkte zum Muster genommen. Sehen wir nämlich dieselben nach, so vermissen wir darin (auch in der ausführlichen 72 Seiten umfassenden) selbst die dürftigste Angabe über das Alter der von ihnen benutzten Bacterienculturen.

Im Uebrigen kann die oben citirte Behauptung Hahn's und Geret's, ich hätte ihnen bezüglich des proteolytischen Enzyms der Tuberkelbacillen falsche Unterstellungen gemacht, gar nicht zutreffen, weil ich im Gegensatz zu Hahn und Geret auf Grund meiner Versuche zu dem Schlusse kam, dass in den Tuberkelbacillen weder ein schwaches noch ein starkes, also überhaupt kein proteolytisches Enzym vorhanden ist. Hahn und Geret könnten demnach wohl behaupten, ich wäre zu falschen Resultaten gekommen, nie aber, ich hätte ihnen falsche Unterstellungen gemacht.

Die Einwendungen, wekche Hahn und Geret gegen meine Resultate erhoben, werde ich besprechen, wenn ich dieselben in dieser Zeitschrift ausführlicher publicire. 